\title{
Consequências da Covid-19 na educação brasileira: análise discursiva de tweets do movimento “\#AdiaEnem”
}

\author{
Joseeldo da Silva Júnior ${ }^{*}$ \\ Ângela Paula Nunes Ferreira** \\ Regina Baracuhy $^{* * *}$
}

\begin{abstract}
Resumo: Este artigo visa analisar a hashtag \#AdiaEnem em tweets reverberados nesta mídia social, a fim de discutir o contexto socioeducacional brasileiro durante o período da pandemia da Covid-19. Para tanto, utilizamos o "método arqueogenealógico" de Michel Foucault, com análises que possibilitaram discutir o tratamento dado pelo governo atual aos estudantes mais pobres, afetados diretamente pela interrupção das aulas. Verificamos que o ativismo virtual através do movimento \#AdiaEnem tornou-se imprescindível para que o calendário do Enem sofresse alteração, demonstrando a importância das redes sociais como espaço de resistência. $\mathrm{O}$ protesto provocou um debate na sociedade sobre a precariedade do ensino público.
\end{abstract}

Palavras-chave: \#AdiaEnem. Coronavírus. Escolas públicas.

\begin{abstract}
This article aims to analyze the hashtag \#AdiaEnem in tweets reverberated on this social media, in order to discuss the Brazilian socio-educational context during the Covid-19 pandemic period. For this purpose, we use Michel Foucault's "archeogenealogical method", with analysis that made it possible to debate the treatment given by the current government to the poorer students, directly affected by the absence of classes. We verified that the virtual activism through the \#AdiaEnem movement became essential for the calendar of the exam to change, demonstrating the importance of social media as a resistance space. The protest provoked a debate in society about the precariousness of the public education.
\end{abstract}

Keywords: \#AdiaEnem. Coronavirus. Public schools.

Resumen: Este artículo tiene como objetivo analizar el hashtag \#AdiaEnem en los tweets reverberados en esta red social, con el fin de discutir el contexto socioeducativo brasileño durante el período de la pandemia Covid-19. Para ello se utilizó el "método arqueogenealógico" de Michel Foucault, con análisis que permitieron discutir el trato que el actual gobierno da a los

\footnotetext{
* Mestre em Linguística pela Universidade Federal da Paraíba (UFPB). Membro do Círculo de Discussões em Análise do Discurso (CIDADI). http://orcid.org/oooo-0002-3872-9425

${ }^{*}$ Doutoranda em Linguística pela Universidade Federal da Paraíba. Professora do Centro de Educação Superior Reinaldo Ramos-CESREI. http://orcid.org/0000-0003-1097-0329

${ }^{* * *}$ Professora Associado Nível IV no Departamento de Letras Clássicas e Vernáculas (DLCV) e no Programa de Pós-graduação em Linguística (PROLING) da Universidade Federal da Paraíba. http://orcid.org/oooo0003-2867-6806
}

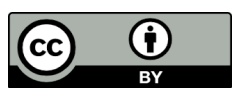

Este artigo está licenciado sob forma de uma licença Creative Commons Atribuição 4.0 Internacional, que permite uso irrestrito, distribuição e reprodução em qualquer meio, desde que a publicação original seja corretamente citada. https://creativecommons.org/licenses/by/4.0/deed.pt_BR. 
estudiantes más pobres, directamente afectados por la interrupción de clases. Descubrimos que el activismo virtual a través del movimiento \#AdiaEnem se ha vuelto imprescindible para que el calendario Enem cambie, demostrando la importancia de las redes sociales como espacio de resistencia. La protesta provocó un debate en la sociedad sobre la precariedad de la educación pública.

Palabras-clave: \#AdiaEnem. Coronavirus. Escuelas publicas.

\section{Introdução}

Desde que o Exame Nacional do Ensino Médio (Enem) foi implementado como uma política educacional em 1998 e se tornou um instrumento pedagógico para o ingresso nas universidades públicas do Brasil em 2009 (SILVEIRA, 2015), anualmente milhares de estudantes se submetem às provas do exame, que além de democratizar a entrada na universidade pública, também contribui para a pluralização de grupos sociais no interior das instituições de nível superior, conforme aponta Malusá et al. (2014). Excepcionalmente, devido à pandemia do coronavírus que obrigou as autoridades públicas a decretarem distanciamento e isolamento social, ocasionando o fechamento de escolas e universidades de todo o país no ano de 2020, o Enem teve sua edição anual adiada para janeiro de 2021. A maioria das escolas e universidades privadas adotaram métodos de ensino remoto, de acordo com as Portarias 343, 345, 356, 473 do Ministério da Educação (BRASIL, 2020) e parecer do Conselho Nacional de Educação (CNE), emitido em 7 de julho de 2020 , que orientou as atividades não presenciais em todo o país, desde o ensino básico ao ensino superior (BRASIL/CNE, 2020). As instituições de ensino públicas, no entanto, permaneceram, em muitos estados, sem aulas ou tardiamente adotaram as aulas remotas.

Mediante esse cenário, uma série de debates foram travados com a finalidade de discutir o impacto da ausência de aulas dos estudantes das redes pública e privada (MONTEIRO, 2020; PEREIRA et al., 2020) no contexto pandêmico, de modo a discutir propostas e intervenções a serem realizadas para minimizar o impacto do isolamento social e a consequente interrupção do ensino presencial. No entanto, mesmo com o 
desenvolvimento de ações que visaram transpor a barreira do distanciamento e levar conteúdo aos estudantes ${ }^{1}$, sobretudo das instituições públicas, as soluções não foram satisfatórias, haja vista o estado de vulnerabilidade social e econômica de muitos brasileiros (ALVES, 2020). Em virtude disso, passou a ser discutida a manutenção do Enem, pensando nos entraves advindos da ausência das aulas.

Nesse sentido, um movimento intitulado \#AdiaEnem surgiu nas mídias sociais, reivindicando o adiamento da prova, justificado pelo fato de que os estudantes em vulnerabilidade social, que estão sem acesso às aulas presenciais, seriam prejudicados em detrimento dos alunos com maior condição social e financeira. Por meio do site "Adia Enem", mantido e administrado pelas entidades sociais estudantis UBES (União Brasileira dos Estudantes Secundaristas) e UNE (União Nacional dos Estudantes), assinaturas foram coletadas para que ocorresse a suspensão das provas. Na cartadivulgação do movimento, as entidades explicam que "é um absurdo pensar que os estudantes estão em igualdades de condições nessa situação e que as atividades à distância poderiam solucionar o problema da suspensão das aulas" (ADIA ENEM, 2020, $\mathrm{s} / \mathrm{p})$.

O então Ministro da Educação, Abraham Weintraub, por outro lado, desconsiderou o adiamento e desdenhou do movimento, o qual considerou ser produzido pela oposição com vistas às questões políticas e econômicas, salientando que o Enem "não é feito para atender injustiças sociais, e sim para selecionar os melhores candidatos" (WEINTRAUB, 2020, s/n). O posicionamento de Weintraub, além de demonstrar uma visão meritocrática, esbarra nas desigualdades sociais de estudantes que não possuem acesso à internet, de maneira a impossibilitá-los a outra via de estudo, a não ser as tradicionais aulas presenciais, fora de cogitação na pandemia pelo altíssimo risco de contágio do vírus em um país que já possui mais de 150 mil mortos pela Covid19.

\footnotetext{
${ }^{1}$ Apenas para citar um exemplo, na Paraíba, o Governo Estadual desenvolveu um aplicativo, com acesso à internet limitado, para que os alunos da rede pública possam ter acesso a uma gama de conteúdo on-line. Matéria sobre o assunto disponível em: <https:/g1.globo.com/pb/ paraiba/ noticia /2020/o7 /o6/ governo-da-pb-disponibiliza-aplicativo-com-internet-gratuita-para-alunos-e-professores.ghtml>. Acesso em o9 de jul. 2020.
} 
Assim, neste artigo, propomos analisar o enunciado-acontecimento \#AdiaEnem em tweets reverberados nesta mídia social, com vistas a discutir o contexto social e educacional e seus efeitos durante o período da pandemia da Covid-19 no Brasil. Para isso, constituímos um corpus formado por mensagens publicizadas no Twitter, a fim de nos possibilitar compreender as condições de emergência das reinvindicações que culminaram no adiamento da prova do Enem. A justificativa para trabalhar com tweets advém da importância dessa prática discursiva, uma vez que o público do Enem é composto por jovens e as redes sociais hoje são um componente indispensável na vida dos estudantes, vistas como o locus por onde acontece a troca discursiva entre eles e a sociedade, além de as hashtags se constituírem um dos lugares de memória da atualidade, em que os dizeres de uma dada formação discursiva se conectam em rede e reverberam infinitamente na web.

Este artigo se ancora no campo dos Estudos Discursivos Foucaultianos. Metodologicamente, a pesquisa empreendida é do tipo qualitativo com viés interpretativo-descritivo, uma vez que analisamos os fatos sob a luz das questões sociais. No que diz respeito à estrutura, este artigo está dividido em quatro seções: a primeira seção discute o método arqueológico fundado por Michel Foucault; em seguida, pontuamos o conceito de enunciado discursivo; o terceiro tópico aborda as análises dos tweets, suscitando uma discussão social sobre as questões pertinentes ao processo de adiamento da prova do Enem; na última seção, traçamos algumas considerações finais a respeito do cenário brasileiro provocado pela pandemia do coronavírus, cujo reflexo na educação pública brasileira parece ter resultado no aprofundamento da desigualdade social, no que tange o acesso ao ensino superior da classe de alunos pobres do país.

\section{Método arqueológico: breves notas}

Na abertura de "A Arqueologia do Saber", Foucault (2010) demarca uma posição crítica sobre a noção de História, fazendo evidenciar um contraste entre a História tradicional e a nova História. Durante muito tempo, nos diz Foucault (2010), os 
historiadores se preocupavam em estudar os grandes períodos em uma rede de causalidade linear entre os acontecimentos oficiais numa lógica evolutiva. Esta perspectiva, no entanto, foi questionada pelos historiadores da Escola dos Annales, que problematizavam o continuísmo presente na história tradicional e propunham analisar a História por rupturas e dispersões. Sobre isso, Foucault (2010) sintetiza:

Em suma, a história do pensamento, dos conhecimentos da filosofia, da literatura, parece multiplicar as rupturas e buscar todas as perturbações da continuidade, enquanto a história propriamente dita, a história pura e simplesmente, parece apagar, em benefício das estruturas fixas, a irrupção dos acontecimentos (FOUCAULT, 2010, p. 06).

A crítica que Foucault teceu a respeito do olhar da História para os acontecimentos constitui o que chamamos de método arqueológico, inscrito na primeira fase do pensamento foucaultiano, cujo foco era nas condições de emergência dos saberes (a Gramática, a Medicina, etc.). A fase arqueológica também se voltou para a discussão sobre o par documento/monumento. Para Foucault, a história tradicional se interessava pela memorização dos monumentos do passado para transformá-los em documentos, que restabeleceriam a verdade histórica sobre um contexto específico. Restituía-se o passado tomando as palavras do documento, ignorando as margens contidas nele próprio. Com os historiadores dos Annales, "a história mudou sua posição acerca do documento" (FOUCAULT, 2010, p. o7), entendendo-o não mais como uma matéria inerte que determina o que é passado e o que deixa rastros, mas considerando-o como um monumento por meio do qual o historiador pode estabelecer séries, definir unidades, descrever relações, sob a égide da descontinuidade.

A história tradicional se propunha a transformar os documentos em monumentos, conforme defende Foucault (2010, p. 8), fazendo aparecer outras narrativas, não mais aquelas dos grandes heróis das grandes guerras, mas agora também as dos heróis do cotidiano. Privilegia-se, a partir de então, o documento-monumento em detrimento simplesmente do documento. Faz, com isso, a criação de séries, resultando no tratamento de acontecimentos pequenos, acontecimentos que "fazem a História avançar". Trata-se de um contraponto à história global, em que se atentava ao geral, ao todo, de forma a criar um panorama da sociedade; com o movimento oposto, atribuído 
pelo modo em que se toma o documento-monumento, pois o "problema que se apresenta - e que define uma história geral - é determinar que forma pode ser legitimamente entre essas diferentes séries; que sistema vertical podem formar", por exemplo, evidenciando "séries de séries - ou, em outros termos, que 'quadros' - é possível constituir". (FOUCAULT, 2010, p. 11)

O movimento epistemológico articulado por Foucault possibilitou pensar em uma Análise do Discurso numa perspectiva histórica, como apontam Drumond e Fernandes Junior (2019, p. 263), esclarecendo que "a questão das discursividades se coloca em outros termos que necessariamente passam pela dimensão histórica”, numa ótica que dialoga com os postulados de uma nova História. Segundo Sargentini (2019, p. 35), o objetivo de Foucault, com o método arqueológico, sobretudo no que tange ao método de análise, evidencia quatro noções de princípio regulador, quais sejam: "o acontecimento (em oposição à criação), a série (em oposição à unidade), a regularidade (em oposição à originalidade) e as condições de possibilidade (em oposição à soberania do significante, reconhecendo que o discurso é uma violência que se faz às coisas)".

A fase arqueológica inicia-se com a publicação da obra A História da Loucura (1961), passando pelo lançamento do livro O Nascimento da Clínica (1963), As palavras e As coisas (1966) e, finalmente, A Arqueologia do Saber (1969).

Segundo Sargentini (2019, p. 35), "o ponto de articulação das proposições de M. Foucault com os estudos do discurso construiu-se particularmente em "A arqueologia do saber" e em "A Ordem do Discurso. Em "A Arqueologia", se problematizou as noções de acontecimento, arquivo, enunciado, discurso, indispensáveis para análises de discursos. Sinteticamente, um dos interesses da arqueologia, segundo Drumond e Fernandes Junior (2019, p. 268), é "seu caráter descritivo em percorrer as múltiplas relações que os discursos estabelecem com as práticas sociais, seus enunciados e arquivos, conduzidas por "um conjunto de regras que regulam as práticas discursivas".

Atendo-se à perspectiva de Veiga-Neto (2007), "A Arqueologia do Saber" não é um livro de teorias, mas sim de possibilidades, abrindo brecha para que se utilize delas para fazer disso um método científico com viés discursivo. Assim, com base nas proposições estruturadas sobre o enunciado (GREGOLIN, 2004a; SOUSA, 2013), propomos discutir na próxima seção esta noção, reservando-se apenas às teorizações de 
Michel Foucault, em sua obra-chave, para analistas do discurso - "A Arqueologia do Saber".

\section{$O$ conceito de enunciado em Foucault}

"Átomo do discurso", assim define Foucault (2010) o termo enunciado, considerado pelo autor como unidade elementar do discurso. Esta unidade do discurso não equivale a uma proposição, tampouco a uma frase, sequer pode ser definida como um ato de fala (speech act). Vejamos que, ao desacreditar o enunciado como proposição, Foucault cita dois exemplos: "Ninguém ouviu" e "É verdade que ninguém ouviu”. Embora sejam equivalentes do ponto de vista lógico, o enunciado está no plano do discurso e, por isso, não pode ser submetido às provas de verdadeiro/falso.

Diferentemente da frase, Foucault explica que o enunciado não está ligado a uma "estrutura linguística canônica” (FOUCAULT, 2010, p. 92), isto é, não se define um enunciado, encontrando os elementos constituintes da frase. Observemos a hashtag \#AdiaEnem. Isoladamente, este conjunto de caracteres poderia ser interpretado como uma frase, um conjunto de elementos gramaticais por meio dos quais se expressaria um pedido. No entanto, para ser considerado um enunciado, a hashtag \#AdiaEnem deve possuir um sujeito que efetivamente a produziu em um lugar institucional, em um dado momento histórico.

Por fim, quando trata dos atos de fala, o filósofo francês põe em evidência o fato de que existe uma aproximação com o enunciado, no entanto não há o interesse no "ato material que consiste em falar (em voz alta ou baixa) e em escrever (à mão ou à máquina)” (FOUCAULT, 2010, p. 93). O enunciado tem natureza semiológica podendo se configurar como uma "série de signos, de figuras, de grafismos ou traços", não importando "qual seja sua organização ou probabilidade” (FOUCAULT, 2010, p. 95), uma vez que todo esse conjunto o constitui como categoria. Dito isso, faz-se saber ainda que o enunciado se trata de uma 
função de existência que pertence, exclusivamente, aos signos, e a partir da qual se pode decidir, em seguida, pela análise ou pela intuição, se eles "fazem sentido" ou não, segundo que regra se sucedem ou se justapõem, de que são signos, e que espécie de ato se encontra realizado por sua formulação (oral ou escrita) (FOUCAULT, 2010, p. 98).

Vale frisar que língua e enunciado não estão no mesmo nível de existência. Há uma relação talvez paradoxal, histórica entre língua e enunciado. A língua, na perspectiva da Linguística Estrutural, tem sua existência marcada por um sistema de signos abstratos que instituem seu funcionamento. Para exemplificar, Foucault (2010) mostra que as letras de uma máquina de escrever são simplesmente letras soltas, contudo, no momento em que o sujeito as escreve em um papel, seguindo as regras do sistema linguístico, elas se tornam enunciados. É preciso, portanto, que a língua seja posta em funcionamento para que haja enunciado.

Em suma, para Foucault, o enunciado pode ser definido como uma função que apresenta quatro propriedades: o referencial, que "define as possibilidades de aparecimento e de delimitação do que dá à frase seu sentido, à proposição seu valor de verdade" (FOUCAULT, 2010, p. 103). Este referencial delimita um lugar, a condição, um campo de emergência, ao passo que "define as possibilidades de aparecimento do enunciado" (FOUCAULT, 2010, p. 103).

A segunda propriedade da função enunciativa é a posição, que se exerce de acordo com o lugar social ocupado pelo sujeito. Nas palavras de Foucault, o sujeito do enunciado é uma função que pode ser "exercida por indivíduos, até certo ponto, indiferentes, quando chegam a formular o enunciado" (FOUCAULT, 2010, p. 105). Este indivíduo pode vir a ocupar uma série de posições numa determinada série enunciativa, posições variadas e "assumir o papel de diferentes sujeitos" (FOUCAULT, 2010, p. 105).

A terceira propriedade da função enunciativa tem a ver com o campo associado, pois "não há enunciados que não suponham outros enunciados", (FOUCAULT, 2010, p. 110), uma vez que existe um diálogo infinito entre os enunciados, que se constituem como "um nó em uma rede” em uma série de formulações, que se repetem, se transformam e/ou se refutam".

A quarta propriedade do enunciado é que ele possui uma existência material, uma materialidade repetível, ou seja, se efetiva por meio de "um suporte, um lugar, uma data” 
(FOUCAULT, 2010, p. 114). A materialidade repetível possibilita a manutenção e a fixação do enunciado. Ele "circula, serve, se esquiva, permite ou impede a realização de um desejo, é dócil ou rebelde a interesses" (FOUCAULT, 2010, p. 119). Vejamos, por exemplo, o enunciado \#AdiaEnem. Ele se corporificou em várias materialidades distintas, desde uma charge a um tweet, repetidas vezes, com local e data específicas, constituindo, assim, um "regime de materialidade repetível" (FOUCAULT, 2010, p. 115) e provocando o estabelecimento de uma verdade.

A análise de uma série enunciativa leva em conta três princípios: raridade, exterioridade e acúmulo. O primeiro, princípio da raridade, diz respeito àquilo que pode ou não ser dito, as regras que possibilitam um sujeito falar ou silenciar-se. "Os enunciados devem ser estudados no limite que os separa do que não está dito, na instância que os faz surgirem à exclusão de todos os outros" (FOUCAULT, 2010, 135), uma vez que o interesse é "definir um sistema limitado de presenças" do enunciado. Parte-se da ideia de que o enunciado possui um lugar próprio, ou seja, está apoiado em uma materialidade, possui uma base material linguística, pois, conforme dita Foucault, ele "ocupa um lugar que só a ele pertence" (FOUCAULT, 2010, 135).

O princípio da raridade se relaciona com o princípio da exterioridade, que por sua vez, se relaciona com a história, ao levar em conta aquilo que está dito em outro espaço temporal, bem como "retomar enunciados conservados ao longo do tempo e dispersos" (FOUCAULT, 2010, p. 137). Para isso, requer do analista um gesto que resgate da história serial enunciados realizáveis, posto em um domínio enunciativo, "do qual certas figuras e certos entrecruzamentos indicam o lugar singular de um sujeito falante e podem receber o nome de um autor", conforme explica Foucault (2010, p. 139), explicitando, ainda, que "'não importa quem fala", mas o que ele diz não é dito de qualquer lugar". (FOUCAULT, 2010, p. 139). Foucault argumenta que se considere o enunciado no cerne de um regime de dispersão, de forma a apreender a sua irrupção no tempo e no lugar em que se produziu, libertando-se de um cogito ou de uma subjetividade fundadora.

O último princípio, o acúmulo, nos faz refletir a partir da seguinte questão: "O que faz com que certos discursos sejam esquecidos e que outros sejam permanentes conservados?" (GREGOLIN, 2004b, p. 35). Certamente, o depósito de enunciados, resultado do acúmulo, reverberação de determinado dito que ocupou diferentes 
espaços-temporais. Tomemos novamente o exemplo do enunciado \#AdiaEnem. Vejamos que ele tomou grandes proporções, haja vista que houve acúmulo do enunciado em distintas materialidades discursivas, iminentemente digitais, tanto em formato de charges, como memes ou fotografias. É um enunciado que está permanentemente conservado. Outros enunciados, no entanto, permanecem no ralo da história, são esquecidos, muitas vezes efêmeros e, portanto, não estabelecem relação com outros enunciados.

A hashtag \#AdiaEnem atende aos três princípios enunciativos (raridade, exterioridade e acúmulo). No que toca ao princípio da raridade, os sujeitos ativistas usam a plataforma do Twitter para livre manifestação, o que possibilita o aparecimento do discurso de adiamento. Como ensina Foucault (2014, p. 35), "ninguém entrará na ordem do discurso se não satisfazer a certas exigências ou se não for, de início, qualificado para fazê-lo", logo temos que os internautas obedecem às regras discursivas que permitem a aparição dos protestos virtuais que promovem o pedido de adiamento do Enem.

Sobre a exterioridade, há uma retomada indispensável do discurso de vulnerabilidade historicamente situada no cenário brasileiro. Este, aliás, é a emergência do discurso. Dada a dificuldade econômica e social dos alunos da rede pública, há menor chance do ingresso no ensino superior. Finalmente, o acúmulo, cujo princípio é ordenado na reverberação enunciativa. A hashtag, enquanto prática discursiva possibilita, por si só, o acúmulo de várias narrativas discursivas. De acordo com Ferreira (2019, p. 44), "a hashtag cria um jogo discursivo, produz enunciados, reúne em um só espaço várias ideias e comentários acerca de determinada temática”, produzindo no enunciado o acúmulo necessário para fazê-lo uma função.

\section{Movimento \#AdiaEnem: a resistência será tuítada}

Segundo o Instituto Brasileiro de Geografia e Estatística - IBGE --, através da Pesquisa por Amostra de Domicílios Contínua - Tecnologia da Informação e Comunicação, cerca de uma a cada quatro pessoas não possui acesso à internet, o que 
representa, em números gerais, aproximadamente 46 milhões de brasileiros que não se conectam à rede (IBGE, 2020). Os dados são referentes aos três últimos meses do ano de 2018, os quais revelam que houve um crescimento no acesso de brasileiros à internet em relação ao ano de 2017 , registrando a marca de $74,7 \%$. No entanto, ainda há $25,3 \%$ que não têm acesso à rede, sendo que nas áreas rurais o número é maior se comparado às áreas urbanas.

A reportagem de Soprana (2020) para a "Folha de São Paulo" traz outros dados acerca desta realidade: mais de 70 milhões de brasileiros não dispõem de acesso à internet ou, quando possuem, o acesso é precário. A pandemia do coronavírus e o distanciamento social, advindos desse problema de saúde pública, revelam uma profunda desigualdade social no que diz respeito ao acesso à internet no Brasil. Tais dados apenas reforçam o movimento “\#AdiaEnem”, que denuncia a falta de oportunidade para grande parcela dos estudantes mais vulneráveis, que não estão tendo preparo suficiente e necessário para participar do Enem, haja vista as suspensões das aulas nas escolas públicas brasileiras. Uma série de manifestações tem sido realizadas nas mídias sociais usando a hashtag \#AdiaEnem a exemplo do tweet contido na Figura 1.

Figura 1: Protesto virtual \#AdiaEnem

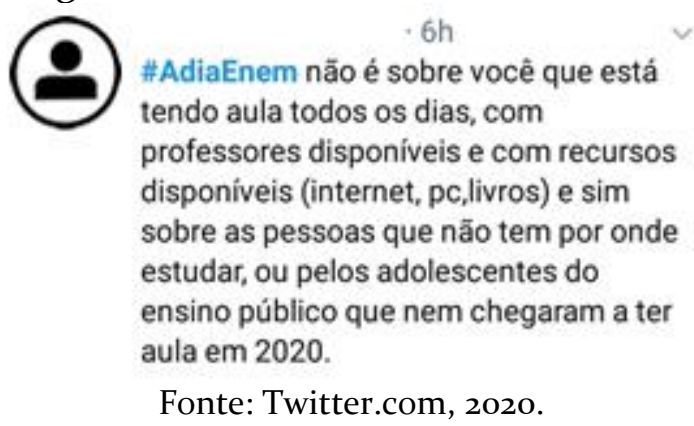

A internauta afirma que a reivindicação do adiamento do Enem não se destina aos estudantes com aulas diárias, mesmo que remotas, "com professores e recursos disponíveis (internet, PC, livros), mas sim àqueles que "não têm por onde estudar" e até mesmo "adolescentes do ensino público que nem chegaram a ter aula em 2020". Essa internauta, que também passa a ser ativista, ao assumir a posição-sujeito de militante, 
corrobora com os dados de que milhões de brasileiros não têm acesso à internet, além de enfatizar o fato de que os estudantes em vulnerabilidade social estão sem aulas presenciais, contrastando com a realidade de alunos da rede privada, os quais dispõem de materiais pedagógicos, cursos on-line e professores exclusivos em regime de educação à distância (EAD). A Pesquisa do Instituto de Estudos Socioeconômicos (Inesc), divulgado na Revista Época, revela que as escolas privadas “adotaram rapidamente o ensino à distância enquanto os colégios públicos ainda não receberam diretrizes do Ministério da Educação e não possuem equipamentos e programas necessários para implementar as aulas e provas pela internet" (CARVALHO, 2020, s/p).

Embora haja esforço do poder público em criar ações educacionais que visam a mitigar as consequências das interrupções das aulas para a população de estudantes carentes, ainda há o fator financeiro que impossibilita os mais pobres de terem acesso às ferramentas virtuais disponibilizadas pelos governos estaduais e municipais. Nesse sentido, os estudantes de escolas particulares que detêm maior poder aquisitivo, consequentemente maior acesso às tecnologias, não se prejudicam tanto sem as aulas presenciais. Além das aulas remotas e cursos de redações, as instituições de rede privadas instituíram um drive thru para entrega de material didático, não apenas como modo de fazer chegar o conteúdo aos seus alunos, mas também de protegê-los da contaminação pelo coronavírus.

Seguindo com a análise do próximo tweet (Figura 2), temos uma informação que revela outro dado: “4,8 milhões de estudantes não conseguem estudar em meio à pandemia por falta de acesso". Este número se refere a uma pesquisa encomendada pelo Fundo de Nações Unidas para Infância (Unicef) em que se constatou, no período pandêmico, essa quantidade de crianças e adolescentes sem conectividade à internet em suas residências. Este dado traça um panorama da desigualdade social e econômica que inviabiliza esse percentual de estudantes de ter acesso aos conteúdos educacionais na crise provocada pela pandemia. Vejamos o tweet. 
Figura 2: Tweet pede adiamento do Enem

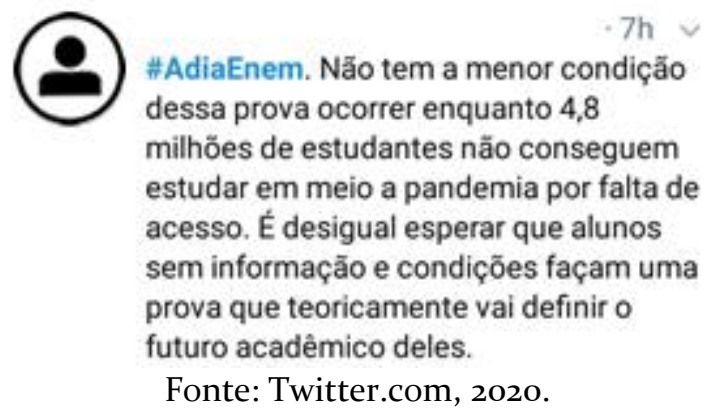

O panorama numérico revelado pela ativista se alinha ao entendimento de Barros (2014, p. 1057) ao perspectivar o acesso no ensino superior do país pelos estudantes mais vulneráveis, que embora tenha "melhorado nos últimos anos, continua sendo vedado à população de baixa renda a entrada nas graduações de maior prestígio e qualidade”, porque as famílias que possuem maior capital cultural, investem mais na escolarização dos seus filhos. Como se vê os estudantes com menor renda dependem exclusivamente das ações do poder público para obterem a menor chance de ter acesso ao conteúdo educativo. No início deste artigo, citamos, em uma nota de rodapé, a iniciativa do Governo da Paraíba em fabricar um aplicativo com acesso à internet gratuita para os alunos da rede estadual de ensino. Intitulado "Paraíba Educa”, a ideia do aplicativo é contemplar o maior número possível de estudantes, de maneira que os possibilite participarem das aulas remotas, numa tentativa de minimizar os efeitos colaterais da inexistência das aulas. Observamos que o conteúdo disponibilizado será restrito ao uso do celular, a única ferramenta para acesso ao material didático.

Outro fato que se deve levar em consideração é a baixa autoestima de estudantes oriundos da rede pública, que, antes da crise, já se tratava de um entrave para prestar a prova do Enem, segundo coloca Barros (2014). Com a pandemia da Covid-19, pode-se imaginar que esta baixa autoestima tenha se potencializado, devido à falta de recursos financeiros e culturais.

A hashtag \#AdiaEnem emerge no contexto de fragilidade econômica e da precariedade social já existentes no país, agora desvelada, uma vez que a pandemia esmiúça os meandros de uma sociedade extremamente desigual e excludente. Mais do 
que isso, demonstra a faceta cruel do Governo atual, ao ignorar as estatísticas e os cenários de pobreza e dificuldade socioeconômica do país.

Na verdade, a existência da hashtag só é possível como estratégia de resistência, em razão da insensibilidade do Governo Federal diante da fragilidade dos 4,8 milhões de estudantes sem possibilidade de acesso aos conteúdos virtuais, sendo talvez o único meio de aprendizado durante a crise sanitária mundial. A fala do Ministro da Educação, trazida no início deste estudo, condensa um pouco do que crê e investe o governo do qual faz parte.

Figura 3: Tweet pede adiamento do Enem

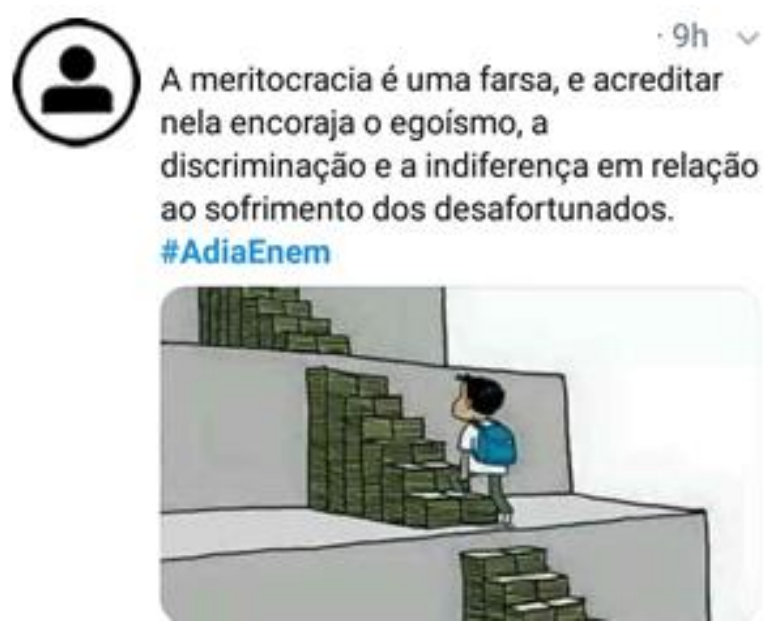

Fonte: Twitter.com, 2020.

No enunciado contido na Figura 3 acima, há uma crítica sobre o discurso meritocrático, com os dizeres: "A meritocracia é uma farsa, e acreditar nela encoraja o egoísmo, a discriminação e indiferença em relação ao sofrimento dos desafortunados” \#AdiaEnem. Na mesma mensagem, consta uma imagem de um personagem, lembrando um aluno, subindo escadas, com os degraus construídos por notas de dinheiro. Isso nos leva a refletir sobre os componentes que definem uma bagagem cultural, quais sejam:

O capital econômico, traduzido em termos de bens e serviços a que ele possibilita o acesso; o capital social, tomado como o conjunto de relacionamentos sociais de prestígio mantidos pela família e o capital cultural institucionalizado, que engloba basicamente os títulos escolares, fazem parte 
da categoria objetiva. Já a categoria subjetiva é formada, sobretudo, pelo capital cultural na sua forma incorporada. (BARROS, 2014, p. 1060).

Não é difícil deduzir, pensando nisso, que a bagagem cultural das camadas mais populares, como um todo, tende a ser precária, senão escassa. Os degraus do sucesso, ora vistos na charge em pauta, requerem o capital econômico e social para que se alcance sucesso escolar, no caso aqui discutido. A responsabilização e a competividade, frutos da meritocracia, passam longe da realidade do país.

A leitura possível, a partir da análise da hashtag \#AdiaEnem, é retomada através de um campo associado escamoteado no sentido produzido pela charge. Embora não esteja dito, reverbera por meio de uma memória social o discurso meritocrático, que emerge em razão do contexto pandêmico, reforçado no manifesto produzido pela internauta.

A aplicação do ensino remoto é, na verdade, o mote que associa a manutenção do ENEM à discussão da meritocracia, pois o processo de ensino-aprendizagem promovido pelas escolas públicas e particulares, sobretudo nas instituições públicas, por meio das aulas remotas, restringem o desenvolvimento de competências de ensino do aluno, antes desenvolvidas com a presença física do professor. Como mostra Alves (2020), as dificuldades do ensino remoto não se limitam apenas ao poder econômico dos pais e alunos, mas também nas habilidades desenvolvidas pelo corpo docente no manuseio de tecnologias e sítios eletrônicos, a exemplo do Google Classroom e Google Meet, para a atuação a distância. Soma-se a isso os possíveis transtornos domiciliares e de vizinhança, impactando diretamente na concentração e na aprendizagem do alunado.

Mas, está na periferia brasileira, o maior desafio, por isso é razoável afirmar que o ensino remoto implica em singular desvantagem aos menos favorecidos. $\mathrm{O}$ ensino a distância ${ }^{2}$ revela-se um problema para as classes vulneráveis, embora, nos últimos anos, tenha se vendido essa modalidade de ensino como uma benesse para a educação, com o propósito de atender ao mercado neoliberal, como mostra Santos (2020), pontuando

\footnotetext{
${ }^{2}$ Vale pontuar que Ensino a Distância (EAD) e Ensino Remoto não são sinônimos, como falsamente podese supor. Ensino à Distância pressupõe a mediação por tutores e professores, com material e estratégia pedagógica claramente definidas. Já o Ensino Remoto, considerado aqui o contexto pandêmico, é uma modalidade em que as aulas compreendem o distanciamento geográfico, conforme aponta Behar (2020), classificando esse modelo de Ensino Remoto Emergencial (ERE), dado as configurações impostas pelo coronavírus. Para a autora, inexiste, no Ensino Remoto, o planejamento pedagógico.
} 
ainda que, em 2019, o governo brasileiro anunciou a extensão do ensino a distância para a educação básica. Anteriormente, essa modalidade de ensino limitava-se, apenas, aos cursos superiores.

Mas voltando ao tweet, ressoa nele a ideia de elitização do ensino superior. A fala do então Ministro da Educação, trazida no início deste artigo, ao justificar a manutenção do calendário do Enem, pelo fato de que a aprovação no exame é para os melhores, produz um reforço na seletividade social, dando enfoque apenas aos estudantes da classe elitista, privilegiando-os, pois ignora as particularidades de estudantes de classes baixas. A ideia de privar o ensino superior aos mais pobres lembra, ainda, a fala do primeiro Ministro da Educação do Governo Bolsonaro, Ricardo Vélez-Rodriguez (2019, s/p), ao afirmar que "as universidades devem ficar reservadas para uma elite intelectual", pois, de acordo com o ex-ministro, não é um espaço para todos. Vejamos que há uma conduta que nivela de cima para baixo quem deve ou não ingressar no ensino superior, notadamente aqueles que detêm maior bagagem cultural.

Seguindo para o último tweet em análise, a hashtag \#AdiaEnem faz uma crítica ao Ministério da Educação e à propaganda de divulgação da edição do Enem, mesmo diante da crise sanitária e do apelo do movimento que visou a manutenção do calendário do exame. Diz o internauta: "Essa propaganda do Ministério da Educação é um absurdo. É o total desconhecimento da realidade dos estudantes do Brasil”. O vídeo em questão foi veiculado na mídia trazendo os dizeres "E se uma geração de novos profissionais fosse perdida? Médicos, enfermeiros, engenheiros, professores. Seria o melhor para o nosso país? A vida não pode parar. É preciso ir à luta, se reinventar, superar”, incentivando ainda que o aluno candidato "estude de qualquer lugar, de diferentes formas" (YOUTUBE, 2020). A crítica do internauta concentra-se nas desigualdades existentes no país e na ignorância do governo brasileiro ao cenário pandêmico que resultou na interrupção das aulas de escolas públicas e as dificuldades decorrentes do ensino remoto. Observemos o tweet: 
Figura 4: Tweet pede adiamento do Enem

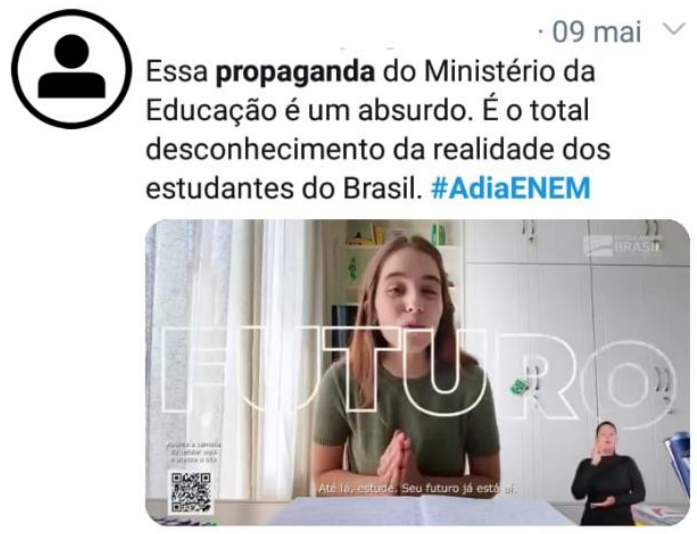

Fonte: Twitter.com, 2020.

A peça publicitária causou revoltas em estudantes nas redes sociais, que se manifestaram contra a falta de sensibilidade do governo federal em insistir no calendário da prova. Conforme nos diz Santos (2020), a crise pandêmica privilegia uns em detrimento de outros, de modo que os possíveis beneficiários do isolamento social e educação remota, notadamente de escolas da rede privada, tendem a se sobressair em relação aos estudantes da rede pública, cujo reflexo educacional se dá em razão das escassas soluções governamentais para o acesso ao ensino. Para Santos (2020, p. 10), "a política, que devia ser a mediadora entre as ideologias e as necessidades e aspirações dos cidadãos, tem vindo a demitir-se dessa função”, revelando-se assim, em certa medida, acolhedora de determinada ideologia em detrimento de outra.

A crise na educação, especialmente no ensino a distância, faz refletir sobre as impossibilidades de uma política neoliberal. Mais perspicaz do questionar "E se uma geração de novos profissionais fosse perdida?", como propõe o vídeo, incrustado no medo, é perscrutar "Quando se recuperarão os atrasos na educação e nas carreiras?" (SANTOS, 2020, p. 29).

\section{Considerações finais}


O ativismo virtual através do movimento \#AdiaEnem tornou-se imprescindível para que o calendário do Enem sofresse alteração, demonstrando a importância das redes sociais como espaço de resistência. Porém, mais do que uma demonstração de resistência a um pleito único, o protesto provocou um debate na sociedade sobre a precariedade do ensino público brasileiro, além de desvelar, ainda mais, as desigualdades sociais que existem no país. Há um grande abismo entre o ensino privado e o ensino público, que, embora possa ofertar condições de ensino remoto, não é alcançado por uma grande parcela dos estudantes, em razão da escassez de recursos e do contexto socioeconômico no qual estão inseridos.

Por outro lado, há de se observar também a indiferença do Ministério da Educação do Governo Bolsonaro perante a realidade do Brasil, ignorando os fatos e os dados, jogando os pobres à própria sorte. O discurso oficial do atual governo aponta que não há uma preocupação na democratização do ensino superior, que, ao que parece, deve ser restrito apenas à elite econômica do país.

O fôlego dado aos estudantes mais vulneráveis com o adiamento das provas do Enem trata de uma solução paliativa, uma vez que as aulas das escolas públicas continuam suspensas em toda a nação, com o prazo a ser estendido, a depender da disseminação do novo coronavírus no país. Até a finalização deste manuscrito, 75.366 mortes haviam sido confirmadas e 1.966.748 de casos notificados oficialmente. Em muitos estados, embora esteja havendo a flexibilização do isolamento, a voltas às aulas presenciais ainda era um ponto a ser discutido. Em São Paulo, de acordo com o governo estadual, as aulas podem ser retomadas em 8 de setembro, na condição de que as unidades de saúde e o número de casos da doença não estejam elevados.

O adiamento do Enem procura dar uma resposta à sociedade, mas é uma resposta tímida e, ousamos dizer, insuficiente, uma vez que as consequências causadas pela pandemia do coronavírus aos mais pobres são ainda incalculáveis; prevê-se que a desigualdade social seja ainda mais aprofundada no nosso país. Até o momento da finalização deste artigo, foi noticiado que a edição do Enem em 2021 poderia ser suspensa em razão da falta de verba para a realização do exame, evidenciando aí um dos problemas socioeducacionais causados pelo coronavírus e que reflete diretamente na vida de milhões de estudantes brasileiros, sobretudo dos mais vulneráveis, que enxergam 
na educação um elemento para resistir às dificuldades implementadas pelo sistema capitalista.

\section{Referências}

ADIA ENEM. Adia Enem. 2020. Disponível em: <https://www.adiaenem.com.br>. Acesso em: o1 jun. 2020.

ALVES, L. Educação remota: entre a ilusão e a realidade. Interfaces Científicas Educação. v. 8, n. 3, 2020.

BEHAR, P. A. O Ensino Remoto Emergencial e a Educação a Distância. Rio Grande do Sul: UFRGS, 2020. Disponível em: https://www.ufrgs.br/coronavirus/ base/artigo-oensino-remoto-emergencial-e-a-educacao-a--distancia/. Acesso em 12 out. 2020.

BRASIL. Ministério da Educação. Gabinete do Ministro. PORTARIA № 343, DE 17 DE MARÇO DE 2020. Dispõe sobre a substituição das aulas presenciais por aulas em meios digitais enquanto durar a situação de pandemia do Novo Coronavírus - COVID-19. Diário Oficial da União, Brasília/DF, 17 dez. 2020.

BRASIL. Ministério da Educação. Parecer CNE/CP no 11/2020, aprovado em 7 de julho de 2020. Orientações Educacionais para a Realização de Aulas e Atividades Pedagógicas Presenciais e Não Presenciais no contexto da Pandemia. Disponível em:http://portal.mec.gov.br/index.php?option=com_docman\&view=download\&alias=1 48391-pcpo11-2o\&category_slug=julho-2020-pdf\&Itemid=30192>. Acesso em o8 jul. 2020. BARROS, A. S. X. Vestibular e Enem: um debate contemporâneo. Revista Ensaio: Avaliação e Políticas Públicas em Educação, Rio de Janeiro, v. 22, n. 85, p. 1057-90, out./dez. 2014.

CARVALHO, C. Crise do coronavírus aumenta desigualdade entre educação pública e privada. Época, São Paulo, o6 maio 2020. Disponível em: <https://epoca.globo.com/sociedade/crise-do-coronavirus-aumenta-desigualdadeentre-educacao-publica-privada-24411071>. Acesso em 02 jun. 2020. 
FERNANDES JUNIOR, A.; DRUMOND, C. C. Pensar a análise do discurso "com" Michel Foucault: A arqueologia como possibilidade analítica. Interfaces. v. 10, n. 3. 2019.

FERREIRA, Â. P. N; SILVA JUNIOR, J. d. Relações de gênero e embates ideológicos no espaço heterotópico da web. Revista Letras Raras. v. 8, n. 2, 2019.

FOUCAULT, M. A arqueologia do saber. Trad. Luiz Neves. Rio de Janeiro: Forense Universitária, 2010.

A ordem do discurso. Aula Inaugural no Collège de France, pronunciada em 2 de dezembro de 1970. 24. ed. São Paulo: Edições Loyola, 2014.

GREGOLIN, M. R. V. O enunciado e o arquivo: Foucault (entre) vistas. In: SARGENTINI, V e NAVARRO-BARBOSA (Orgs.). M. Foucault nos domínios da linguagem. São Carlos: Claraluz, 2004a.

Michel Foucault: os discursos nas tramas da História. In: FERNANDES, C.A.; SANTOS, J.B.C. (Orgs). Análise do Discurso. Unidade e Dispersão. Uberlândia: Entremeios, 2004b, p. 19-42.

IBGE - INSTITUTO BRASILEIRO DE GEOGRAFIA E ESTATÍSTICA, 2020. PNAD Contínua TIC 2018: Internet chega a 79,1\% dos domicílios do país. 2020. Disponível em: <https://agenciadenoticias.ibge.gov.br/agencia-sala-de-imprensa/2013-agencia-denoticias/releases/27515-pnad-continua-tic-2018-internet-chega-a-79-1-dos-domiciliosdo-pais>. Acesso em 02 jun. 2020.

MALUSÁ, S.; ORDONES, L. L. M; RIBEIRO, E. Enem: pontos positivos para a educação brasileira. Revista Educação e Políticas em Debate. v. 3, n. 2, ago/dez. 2014.

MONTEIRO, S. d. S. (Re)inventar educação escolar no Brasil em tempos da COVID-19. Revista Augustus. v. 25, n. 51, jul./out. 2020.

PEREIRA, A. J.; NARDUCHI, F.; MIRANDA, M. G. de. Biopolítica e educação: os impactos na pandemia de covid-19 nas escolas públicas. Revista Augustus. v. 25, n. 51, jul./out. 2020.

SANTOS, B. de S. A cruel pedagogia do vírus. Coimbra: Edições Almedina, S/A, 2020

SARGENTINI, V. M. O. Há em Foucault um gesto inaugural nos estudos do discurso? Revista Heterotópica, v. 1, n. 1, p. 34-47, 26 jun. 2019.

SOPRANA, P. 70 milhões de brasileiros têm acesso precário à internet na pandemia do coronavírus. Folha de S. Paulo, São Paulo, 16 maio 2020. Disponível em: 
<https://www1.folha.uol.com.br/mercado/2020/05/cerca-de-70-milhoes-no-brasil-temacesso-precario-a-internet-na-pandemia.shtml>. Acesso em 02 jun. 2020.

SOUSA, K. M. A noção de enunciado de Michel Foucault: onde dizer é produzir inovação. Revista da Anpoll, Florianópolis, n. 34, p. 125-157, jan./jun. 2013

SILVEIRA, F. L. d.; BARBOSA, M. C. B.; SILVA, R. d. Exame nacional do ensino médio (ENEM): uma análise crítica. Revista Brasileira de Ensino de Física, SciELO Brasil, v. 37, n. 1, p. 1101. 2015.

VEIGA-NETO, A. Foucault \& a Educação. 2 ed. Belo Horizonte: Autêntica, 2007.

VÉLEZ-RODRIGUEZ, R. 'Ideia de universidade para todos não existe', diz ministro da Educação. [Entrevista concedida a Hugo Passarelli]. Valor, Brasília. 2019. Disponível em: $<$ https://valor.globo.com/brasil/noticia/2019/o1/28/ideia-de-universidade-para-todosnao-existe-diz-ministro-da-educacao.ghtml>. Acesso em: 02 jun. 2020.

WEINTRAUB, A. Exclusivo: Ministro da Educação não descarta adiar data do Enem. [Entrevista concedida a Monalisa Perrone e Caio Junqueira]. CNN Brasil, São Paulo. 2020. Disponível em: <https://www.youtube.com/watch?v=XybBıYo_oM4>. Acesso em o1 jun. 2020.

YOUTUBE. Enem 2020 - Inscrições. 2020. Disponível em: $<$ https://www.youtube.com/watch?v=apufjiGlIYo>. Acesso em 16 jul. 2020. 